\title{
Overview of actions to strengthen financial stability of companies
}

\author{
Fariza Yerdavletova ${ }^{1, *}$, Bayan Ermekbaeva ${ }^{1}$, Gulnar Zhunissova ${ }^{1}$, Zhanar \\ Mukhametzhanova ${ }^{1}$
}

${ }^{1}$ Al-Farabi Kazakh National University, al-Farabi Ave. 71, 050040 Almaty, Kazakhstan

\begin{abstract}
Based on a review of the recommendations of various scientists, the article presents measures to strengthen the solvency and financial stability of companies in various fields of production. These include effective receivables management, accelerated capital turnover, increased profits and cash flow. The article reveals the concept of financial stability as the main criteria of the company's financial condition. As well the negative aspects of the financial condition of companies are discussed. All negative factors divided into three groups based on their characteristics: general economic factors, state factors, and market factors. The model of accounts receivable management, which includes three stages is presented. It is concluded that a high share of accounts receivable as part of assets can lead any company to loss of solvency. Ways to improve the structure of funding sources, aspects of increasing return on capital are considered. Several recommendations given to reduce the duration of capital turnover in order to increase the company's solvency. As a factor of increasing profits a possible ways of minimizing costs are investigated. Ways of increasing production volumes are highlighted and described, measures to increase cash flow are analyzed. Considerable attention is paid to the irrational management of cash flows.
\end{abstract}

\section{Introduction}

The criterion of "financial stability" is always relevant and is considered one of the main characteristics of the financial condition of the company. Let us consider briefly what is meant by the term "financial stability". In modern economic literature, there are several interpretations of the financial stability of the company.

\section{Literature review}

So, in the economic and legal dictionary of A. Azriliyan [1] by financial stability is understood as "... the stability of the financial situation, expressed in the balance sheet of finances, sufficient liquidity of assets, the availability of necessary reserves." According to T. I. Mukhambetov, the economic essence of financial stability is to ensure stable solvency due to a sufficient share of capital in the sources of financing [2]. A. D. Sheremet, R. S.

\footnotetext{
* Corresponding author: vip.erdavletova@mail.ru
} 
Sayfullin indicate that financial stability is one of the most important characteristics of the financial condition of a company. From their point of view, the stable financial position of the company is the result of skillful and calculated management of the aggregate and economic factors of production that determine the results of the company [3]. In the audit and accounting dictionary under the editorial supervision of $\mathrm{Zh}$. G. Dzhumagalieva, the financial stability of the company is defined as “... a characteristic testifying to the stable position of the enterprise: excess of income over expenses, free disposal of funds and their effective use" [4]. Determining the limitations of financial stability of companies is one of the most important economic problems in market conditions, since the lack of financial stability can lead to a shortage of funds from the company for the development of production, its insolvency and, ultimately, bankruptcy and "excess" of resistance will hamper development, a burden for companies with unnecessary costs and stocks. Different approaches are based on the fact that some authors consider the financial resistance of the company to be one of the characteristics of the current financial situation of the company. [5]. Another approach is that the analysis of financial stability is considered an assessment of the stability of the company both now and in the future [6]. These approaches can be described as static and dynamic. It should be assumed that the dynamic approach is more consistent with the orientation of objective financial analysis: the sound development of managerial decisions, the impact of which on the financial position of the company should appear in the future. At the same time, the economic essence of the financial stability of a company is the availability of its reserves and costs for its own and borrowed sources of formation of fixed and circulating production assets [7]. Some proponents of this approach explain that, in contrast to the concepts of "solvency" and "creditworthiness," the concept of "financial stability" is broader, since it includes an assessment of various aspects of the company [8].

\section{Methodology}

The methodology of this study is based on the principles of system-structural analysis, based on the application of comparison and generalization methods, scientific analysis and synthesis to the study of the performance characteristics of companies engaged in the production sector.

The theoretical and methodological basis of the study was the scientific works of domestic and foreign scientists-specialists in this field of analysis of strengthening the financial stability of companies. The main result of this study is to identify the efficiency of production by applying factor analysis.

\section{Results and Discussion}

Exploring the aspect of financial stability, many companies consider the problem of having a large share of receivables to be a problem. In order to reduce accounts receivable, its effective management is necessary; for this, strict control and monitoring of its quality should be carried out.

It is no secret that accounts receivable are a source of repayment of a company's accounts payable. In the event that the company has suspended the balance in settlements with buyers and customers, the company may experience a sharp shortage of funds, which will entail the occurrence of payables, delays in tax liabilities, social security contributions, liabilities for wages and other payments. This will lead to the calculation of fines, penalties, forfeits, as well as to other negative consequences. Each social life area has different approaches to define this notion and its boundaries. In spite of some expected favorable financial effect, the 
risk is inextricably bound up with probable material loss which can be caused by an unfavorable decision or circumstances, such as changes in market conditions or force majeure.

Ignoring contractual debts and late settlements with contractors will result in the loss of goodwill of the company and, in the final result, inability to pay the debt [9]. In this regard, the regular analysis and control of accounts receivable, which provides for monitoring the turnover of funds in the calculations, seems to be a positive policy.

There are important internal resources and mechanisms to manage receivables more productively and achieve auxiliary working capital. For the effective control of receivables, it is advisable to take the following recommendations:

- check the situation with the calculations of buyers and timely file claims;

- arget the largest number of customers in order to reduce the risk of non-payment by one or more large customers;

- monitor the consistency of payables and receivables.

In order to effectively manage receivables, a receivables management model is recommended that includes the three steps shown in the Figure 1.
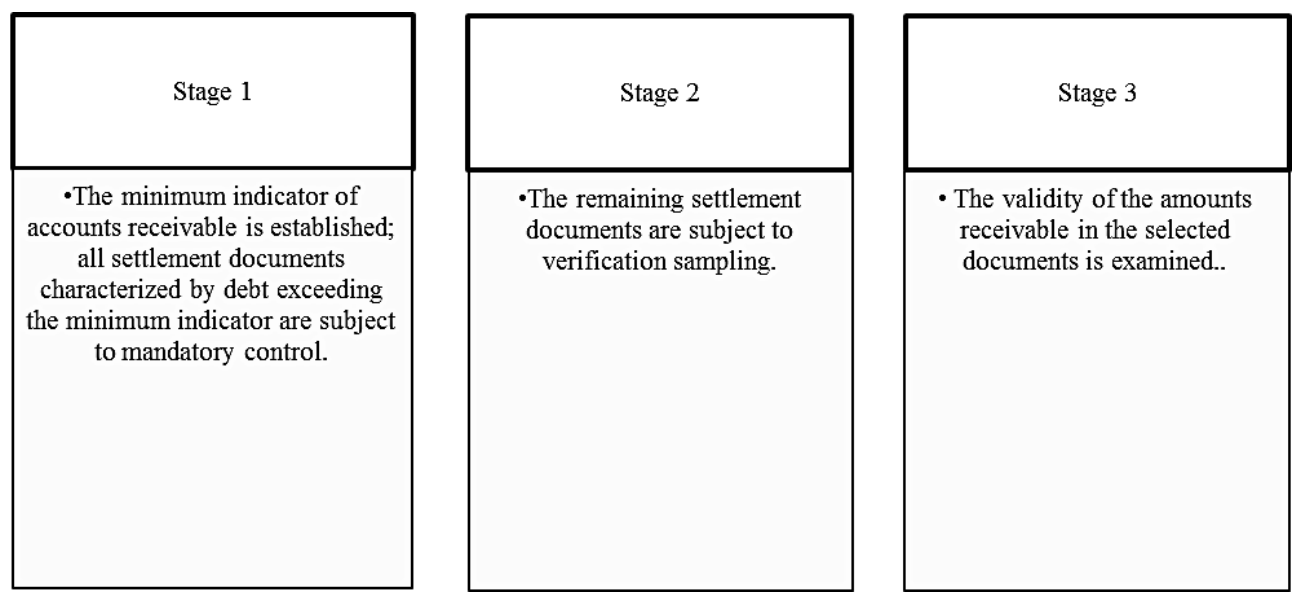

Fig. 1. Accounts receivable management model [9]

Therefore, the presence of a high share of receivables in assets can lead to any companylosing solvency. Taking into account the important role of the solvency of the company in ensuring its financial stability, it is natural that any company or firm will strive to implement measures to increase its solvency and find appropriate methods.

In such cases, first, it is necessary to identify which solvency and liquidity conditions of the company affect its financial condition. Such conditions may be - general economic factors (inflation, unemployment, etc.), state (instability of the tax system, political instability, etc.) and market (lack of state support, reduced demand for products, financial crises, etc.). To increase the solvency of the company, it is advisable to correct the structure of sources of financing so that more stable sources of financing increase and short-term ones decrease. In addition, it is possible to reduce the need for financial sources by eliminating unoccupied assets and increasing the turnover of short-term funds. In order to increase solvency, the company is also worth increasing its own capital due to retained earnings, for which a certain dividend policy should be created. An increase in the authorized capital by owners and third parties is possible. This can be achieved by attracting contributions from participants and third parties. One of the ways to increase the solvency of a company can be changes in the fulfillment of obligations by transferring the company's debt to its owners with the necessary 
condition that the creditor agrees to transfer the debt. In addition, a company may sign an agreement on the assignment of a claim in exchange for consent to accept a debt, in other words, an obligation to pay off a payable. At the same time, two debts will be reduced simultaneously: payables and receivables [10]. In addition, the company can increase the profitability of its capital due to the rational and economical use of all contained resources, preventing their overruns and losses at all stages of the circuit. Ultimately, capital will return to its original state in a larger volume with profit. Therefore, any company in an effort to improve solvency can carry out the above actions, take appropriate measures, thereby improving its solvency and, therefore, organize even greater financial stability.

The financial stability is also greatly affected by the reduction in the duration of capital turnover. To avoid this, the following recommendations can be made:

1) reducing the duration of the production cycle due to the expansion of production;

2) improving the organization of material and technical support for equipping rhythmic production with the necessary material reserves and reducing the time during which capital is in reserve;

3) reduction of the time of placement of funds in receivables;

4) an increase in the degree of marketing analysis aimed at accelerating the promotion of services from producer to buyer;

5) limitation of the business cycle due to the promotion of trade;

6) negotiating with existing and potential suppliers on ensuring the extension of payment terms;

7) improvement of logistics processes to reduce transport, storage and similar costs.

The effect obtained as a result of an increase in production without an increase in additional financial resources. In addition, he usually returns to the original monetary form with the addition [11]. In the event that the production and sale of products are uncontrollable, this leads to a decrease in financial results. Thus, the company should increase profit by only one tenge, which in turn increases the rate of capital production. Separately, I would like to highlight recommendations for profit and cash flow. If the company has decreased profit, then, in our opinion, it is necessary to increase sales. Our recommendations for a specific aspect of use are below. The factors of increase are the possible ways to minimize costs, indicated in Figure 2.

\begin{tabular}{|c|c|}
\hline Reducing the cost of raw materials & $\begin{array}{l}\text { - Selection of contractors supplying funds at lower prices and deferring } \\
\text { payment; or buy raw materials directly from the manufacturer, reducing } \\
\text { the number of intermediaries. }\end{array}$ \\
\hline Lower energy costs & $\begin{array}{l}\text { - Make the transition to the economical use of energy in the company and } \\
\text { introduce sensors for day / night electricity consumption. }\end{array}$ \\
\hline Reduce staff costs & $\begin{array}{l}\text {-Integration of some related posts, excluding their duplication, mainly of } \\
\text { managerial personnel. }\end{array}$ \\
\hline Reduced equipment operating costs & $\begin{array}{l}\text {-Implementation of the use of return leasing of equipment and } \\
\text { minimization of technological downtime. }\end{array}$ \\
\hline Lower cost of sales & $\begin{array}{l}\text { - Reducing transportation costs by mobilizing the services of a logistics } \\
\text { company, introducing optimal tariff rates and automating the accounting } \\
\text { of products sold. }\end{array}$ \\
\hline Administrative costreduction & - Reduced hospitality and streamlined advertising costs \\
\hline
\end{tabular}

Fig. 2. Ways to minimize costs [12] 
The implementation of these measures, in our opinion, will contribute to the growth of profit of any company. In order to increase sales volumes, there are the following ways to increase sales of products, shown in Figure 3.

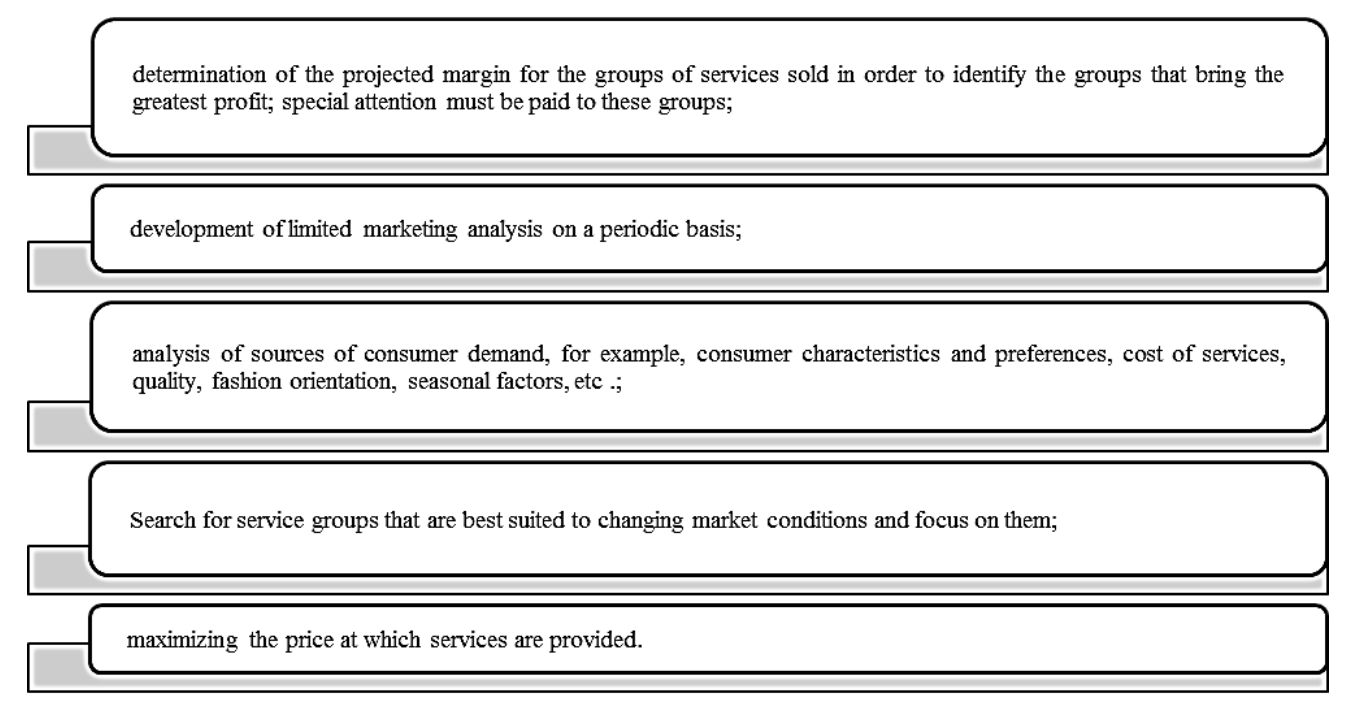

Fig. 3. Ways to increase production [14]

The increase in production can be implemented in the following ways:

- due to a reduction in the balances of commercial products in the warehouse compared to the reporting period;

- from a reduction in the volume of goods shipped but not paid in comparison with the reporting period;

- as a result of the organization of additional jobs;

- from the introduction of new equipment;

- from eliminating the loss of working time;

- from eliminating the loss of equipment operating time;

- from the introduction of measures to develop technology and the organization of production and labor;

- due to the development of the production process and labor;

- from a decrease in the rate of expenditure of raw materials as a result of the introduction of new technologies;

- improving the quality of finished products [14].

When finding ways to increase the sales volume of products, it is advisable to take into account the excess plan balances of finished products in the company's warehouses and delivered to customers. It is also necessary to take into account the demand for the product and the actual probability of its sale.

The company in the interests of increasing the volume of sales can implement the above measures, that is, increase the volume of sales and prevent the deterioration of financial condition.

With the irrational management of cash flows, we can recommend several ways to increase the cash flow, the most effective of them are:

- cost reduction;

- implementation of the conversion of inventory;

- acquisition of additional cash from the operation of fixed assets; 
- $\quad$ segregation of payments to creditors in terms of priority to reduce cash outflows;

- providing an increase in cash inflows through revaluation of capital investment plans;

- an increase in the flow of funds from interested sources of financing that are not related to mutual trade [15].

These paths can be applied using the following measures.

Cost reduction. First you need to consider the likelihood of improving or reducing the cost of labor. To this end, the following measures can be implemented: reduction or termination of premium and other payments, introduction of payments based on the company's results for the quarter or year, reassessment of tariff rates, etc. It is also rational to consider the organizational structure in order to eliminate unnecessary levels of management and reduce costs administrative work.

Implementation of inventory conversion. It is necessary to begin the transformation from the fact that stocks are distributed into groups according to their level of need to increase the stability of the organization. Non-critical stocks for doing business need to be reduced.

If possible, it is advisable to reduce the volume of inviolable stocks by agreeing on a shorter delivery time for goods. This can be done by comparing with the improvement of the company's work in the field of equipment orders with the introduction of more practical control procedures. This may require more intensive work with suppliers on expedited delivery and encouraging them in the form of more attractive payment terms.

It is appropriate to sell reserve stocks at a discount for the acquisition of additional cash. However, one should assume that the risk of oversaturation of the goods market at competitive prices, will negatively affect the subsequent sale and will not allow to implement the strategy of increasing prices.

The acquisition of additional cash from the operation of fixed assets. It is preliminary advisable to analyze the level of operation of equipment and property in order to diagnose a list of property that is not used in current activities. In this situation, it is allowed to discuss with the engineer what equipment is needed to maintain the production rate and opportunities for improving the use of the premises. After that, it is necessary to identify potential buyers or users of surplus property by examining competitors or the likelihood of another use of this property.

Next, you can find the most appropriate communication channels for effectively bringing to market participants recommendations on the sale or leasing of property. Property that could not be rented must be preserved, a conservation act must be submitted to the tax authorities.

Sometimes it is necessary to familiarize yourself with the likelihood of renewing the lease with the lessor, and in the absence of such a likelihood, examine the possibility of transferring activities to a more inexpensive place. It is also possible to centralize activities by transferring units to the same number of places in order to avoid the repetition of business functions in different units and, therefore, free up additional property for sale or leasing.

Separation of payments to creditors in terms of priority to reduce cash outflows. To implement this measure, it is necessary to apportion the contractors according to the level of their need for its activities. Critical suppliers should pay particular attention to; It is advisable to intensify contacts with them in order to strengthen mutual understanding and interest in cooperation.

It is possible to prepare and offer suppliers various payment plans and convince lenders that the new method will be the best way to maintain mutually beneficial relationships. Discuss the issue of deferred payment.

Revaluation of capital investment plans. This is aimed at minimizing costs. Under the threat of crisis, it is rational to backtrack on investments in capital construction, the purchase of new equipment, etc., with the exception of urgent cases. To determine them, it is necessary to analyze what needs for capital investments cannot be removed until a later date. In addition, it is required to abandon capital costs, which will give an immediate return for the 
company.

Investment projects that have become less effective in the course of changes in financial activities should be interrupted [16, 17]. In addition, you need to change the investment schedule in order to reduce the maximum load on the company's cash flows by looking at the investment stages. But at the same time, a further outflow of money should not prejudice the probability of making other urgent payments. Next, it is necessary to calculate the probable costs of closing certain areas, such as the cost of dismantling the equipment, its transportation, reducing staff, etc., as well as comparing them with the likely losses during a period of reduced business activity. Based on this comparison, the capital investment plan should be adjusted.

An increase in the flow of funds from interested sources of financing not related to mutual trade. In this case, we are talking about turning to relations with the main creditors during the crisis - the bank and the owners of the company. You should start with a study of the conditions of short-term financing that the bank offers, and options for improving them. This means, first of all, a reassessment of the company's debt requirements and an analysis of the probability of refinancing loans at other banks.

In the event that there are no other probabilities or sources of financing, you can talk with the owners of the company about the search for alternative financial resources. The threat of the crisis takes into account that the planned dividend payments will be reduced or delayed.

The implementation of these measures will allow, in our opinion, to increase the cash flow, thereby prevent the deterioration of the financial condition.

\section{Conclusion}

In conclusion, among the effective measures to strengthen financial stability, as in the opinion of many other authors, the following should be attributed:

- cost reduction;

- the conversion of inventory;

- the acquisition of additional cash from the operation of fixed assets;

- the separation of payments on loans;

- the provision of an increase in cash inflows due to planned capital investments;

- an increase in the flow of funds from relevant sources of funding;

- increasing the volume of sales. Ways to increase product sales:

- determination of the projected margin for group trading services with the goal of group, bringing the greatest profit;

- development of limited marketing research on a daily or weekly basis;

- prices, quality, fashion trends, seasonal factors, etc.

\section{References}

1. Azrilian A. N., Economic and legal dictionary, 638 (Institute of the New Economy, Moscow, 2014)

2. Mukhambetov T. I., Nukushev A. G., Bankruptcy and anti-crisis management of the enterprise, 607 (Training allowance, Almaty, 2000)

3. Sheremet A. D., Sayfulin R. S., Methodology of financial analysis, 512 (Infra-M, Moscow, 2014)

4. Dzhumagalieva Zh. G., The Russian-English-Kazakh Dictionary of the Accountant and Auditor, 336 (IzdatMARKET, Almaty, 2006)

5. Mukhambetov T. I., Materials of the 2nd International Conference on Management, Leadership and Governance (ICMLG), 202-207 (2014) 
6. R. S. Higgins, The financial analysis. Tools for making business decisions, 464 (WilliamsPublishingHouse, Moscow, 2008)

7. Dyusembaev K. Sh., Analysis of financial statements, 366 (Economics, Almaty, 2009)

8. Wahlen J. M., Baginski S. P., Bradshaw M., Financial Reporting, Financial Statement Analysis, and Valuation: A Strategic Perspective. 8th ed., 1200 (Cengage Learning, 2015)

9. Berezhnykh M. V., Naumova T. A., ISTU Bulletin, 4(99), 1-5 (2015)

10. Kogdenko V. G., Economic analysis: theory and practice, 15(414), 2-14 (2015)

11. Osmonaliev A.O., Arzybaev A.A., Sapalov A.A., Tabirisova R.T., Accounting. Analysis. Audit, 4, 71-80 (2016)

12. Timonina A. S., Plakhov A. V., Young scientist, 12(5), 77-79 (2016)

13. Chernyshova O. N., Fedorova A. Yu., Socio-economic phenomena and processes, 11, 1-8 (2012)

14. Almazova E. S., Zapara E. A., Alley of science, 3(16), 34-37 (2017)

15. Urmanbekova I. F., Young scientist, 17, 391-394 (2017)

16. Mutanov, G., Ziyadin, S., \& Shaikh, A. A., Enterpreneurship and Sustainability Issues, 6(4), 2136-2158 (2019). DOI: 10.9770/jesi.2019.6.4(41)

17. Ziyadin, S., Streltsova, E., Borodin, A., Kiseleva, N., Yakovenko, I., \& Baimukhanbetova, E., Sustainability, 11(9), 2544, (2019). DOI: 10.3390/su11092544 